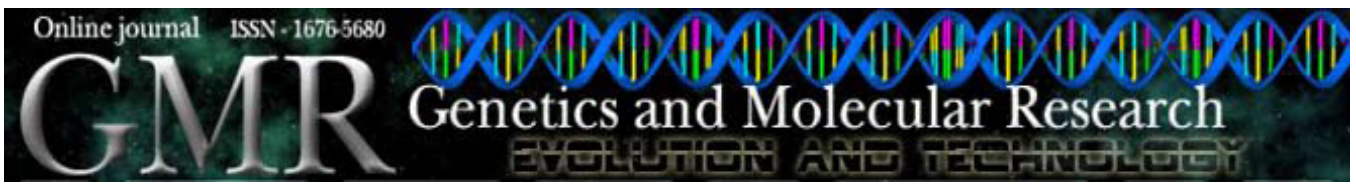

\title{
Caspase-3/-8/-9, Bax and Bcl-2 expression in the cerebellum, lymph nodes and leukocytes of dogs naturally infected with canine distemper virus
}

\author{
H.L. Del Puerto ${ }^{1}$, A.S. Martins ${ }^{2}$, L. Moro ${ }^{1}$, A. Milsted ${ }^{3}$, F. Alves ${ }^{2}$, \\ G.F. Braz ${ }^{4}$ and A.C. Vasconcelos ${ }^{1}$ \\ ${ }^{1}$ Departamento de Patologia Geral, Instituto de Ciências Biológicas, \\ Universidade Federal de Minas Gerais, Belo Horizonte, MG, Brasil \\ ${ }^{2}$ Departamento de Fisiologia e Biofísica, Instituto de Ciências Biológicas, \\ Universidade Federal de Minas Gerais, Belo Horizonte, MG, Brasil \\ ${ }^{3}$ Department of Biology, University of Akron, Akron, OH, USA \\ ${ }^{4}$ Escola de Veterinária, Departamento de Medicina Veterinária Preventiva, \\ Universidade Federal de Minas, Belo Horizonte, MG, Brasil \\ Corresponding author: H.L. Del Puerto \\ E-mail: helendelpuerto@hotmail.com
}

Genet. Mol. Res. 9 (1): 151-161 (2010)

Received October 22, 2009

Accepted November 17, 2009

Published January 26, 2010

\begin{abstract}
Canine distemper is an immunosuppressive disease caused by the canine distemper virus (CDV). Pathogenesis mainly involves the central nervous system and immunosuppression. Dogs naturally infected with CDV develop apoptotic cells in lymphoid tissues and the cerebellum, but this apoptotic mechanism is not well characterized. To better understand this process, we evaluated the expression of Bax, Bcl-2, and caspase- $3,-8$ and -9 , by evaluating mRNA levels in the peripheral blood, lymph nodes and cerebellum of CDV-infected (CDV+) and uninfected (CDV-) dogs by real-time polymerase chain reaction (PCR). Blood samples from $12 \mathrm{CDV}+$ and $8 \mathrm{CDV}$ - dogs, diagnosed by reverse transcription-PCR, were subjected to hematological analysis and apoptotic gene expression was evaluated using real-time-PCR. Tissues
\end{abstract}


from the cerebellum and lymph nodes of four CDV+ and three CDVdogs were also subjected to real time-PCR. No significant differences were found between CDV+ and CDV- dogs in the hemotological results or in the expression of caspase-3, $-8,-9$, Bax, and Bcl-2 in the peripheral blood. However, expression of Bax, caspase- $3,-8$ and -9 was significantly higher in the cerebellum of CDV+ compared to CDV- dogs. Expression of caspase- 3 and -8 was significantly higher in the lymph nodes of CDV+ compared to CDV- dogs. We concluded that infection with CDV induces apoptosis in the cerebellum and lymph nodes in different ways. Lymph node apoptosis apparently occurs via caspase- 3 activation, through the caspase- 8 pathway, and cerebellum apoptosis apparently occurs via caspase- 3 activation, through the caspase- 8 and mitochondrial pathways.

Key words: Apoptosis; Canine distemper virus; Caspases; Cerebellum; Lymph nodes; Real-time PCR

\section{INTRODUCTION}

Canine distemper virus (CDV) causes canine distemper (CD) in dogs and other carnivores and belongs to the genus Morbillivirus within the family Paramyxoviridae. The virus is a highly contagious pathogen that occurs worldwide (Blixenkrone-Moller et al., 1993; Pringle, 1999), and its infection in dogs generally induces a multisystemic disease (Griot et al., 2003). After aerosol infection, initial virus replication takes place in the lymphoid tissues of the upper respiratory tract. CDV-induced alterations of lymphoid tissue include thymus atrophy, depletion of B and T cells and inclusion bodies in reticular and lymphoid cells (Krakowka et al., 1980; Iwatsuki et al., 1995; Wunschmann et al., 2000). Canine distemper virus spreads, at approximately 10 days post-infection, from the primary replication sites to epithelial tissues and reaches the central nervous system, resulting in a demyelinating disease (Vandevelde and Zurbriggen, 2005). In CD, immunosuppression followed by secondary infections is the leading cause of death (Krakowka et al., 1975).

A number of viruses have been shown to cause cell death by induction of apoptosis (Guo and Lu, 1998; Moro et al., 2003b), such as the human immunodeficiency virus (Banda et al., 1992) and the influenza virus (Takizawa et al., 1993). In CDV-infected dogs apoptosis was reported to occur in vitro and in vivo (Guo and Lu, 2000; Moro et al., 2003a). Moro et al. (2003b) and Kumagai et al. (2004) observed that CD causes apoptosis in the lymph nodes. Moro et al. (2003a) also observed apoptosis in the cerebellum, and Schobesberger et al. (2005) observed that CDV infection induced apoptosis of lymphocytes and monocytes. Apoptosis can be triggered by various physiological and pathological stimuli, and it is prevalent in several immunosuppressive diseases of humans and animals (Ameisen and Capron, 1991; Lam and Vasconcelos, 1994). There are two major pathways of apoptosis: the death receptor-mediated external signal pathway - extrinsic pathway, and mitochondrium-mediated internal signal pathway - intrinsic pathway (Finucane et al., 1999; Wajant, 2002). The most important effectors of apoptosis are cysteine aspartic acid-specific proteases (caspases), proapoptotic proteins, which participate in a tightly regulated proteolytic cascade (Slee et al., 2001; Adams and Cory, 2002). In many cell types, apoptosis is controlled by Bcl-2 family 
members, which can be divided into two groups: anti-apoptotic and pro-apoptotic proteins (Adams and Cory, 1998). Anti-apoptotic protein, Bcl-2, acts to regulate the mitochondrial membrane potential and blocks the release of cytochrome-C and apoptosis inducing factor into the cytoplasm (Manon et al., 1997; Shimizu et al., 1998). Under various circumstances, the activity of the Bcl-2 protein may be regulated through caspase cleavage (Clem et al., 1998). The balance between pro-apoptotic and anti-apoptotic proteins is thought to determine cell death or survival by controlling apoptosis (Oltvai et al., 1993). Little is known about the apoptotic molecular mechanisms involved in $\mathrm{CD}$ disease pathogenesis in vivo. In this regard, the aim of the present study was to evaluate mRNA expression of pro-apoptotic Bax, caspase- $3,-8$ and -9 , and anti-apoptotic Bcl-2, in different tissues of dogs naturally infected with CDV and in non-infected dogs, in order to understand the apoptotic pathway induced in $\mathrm{CD}$ disease.

\section{MATERIAL AND METHODS}

\section{Animals}

\section{Blood sample collection}

Blood samples $(5 \mathrm{~mL})$ from 20 domestic dogs presenting clinical signs suggesting $\mathrm{CD}$ (including listlessness, decreased appetite, fever, and oculonasal discharge), and 12 domestic dogs with no clinical signs of $\mathrm{CD}$ were collected. An aliquot of $1 \mathrm{~mL}$ was immediately placed on dry ice, and transferred to a $-80^{\circ} \mathrm{C}$ freezer until use. A second aliquot was used for hematological analysis, performed in the clinical pathology laboratory at UFMG School of Veterinary Medicine. Dogs were of mixed breeds, ages, and sexes and had no signs of other infections. Blood samples were collected in two veterinary clinics from Belo Horizonte, MG, Brazil, after owner consent, and in the Center for Zoonoses Control (Centro de Controle de Zoonoses) of Belo Horizonte, MG, Brazil.

\section{CDV diagnosis}

Dogs were diagnosed for CDV using conventional gel-based reverse transcriptionpolymerase chain reaction (RT-PCR) and checked again using real-time PCR quantitative diagnosis. After that, animals were divided into two groups: CDV positive (CDV+) and CDV negative (CDV-) animals.

\section{Necropsies and tissue samples (cerebellum and lymph node)}

Necropsies of 4 of $12 \mathrm{CDV}+$ animals were performed after euthanasia. Animals presented neurological and systemic clinical signs of CDV infection. Portions of the cerebellum and retropharyngeal lymph nodes were snap frozen in liquid nitrogen and stored at $-80^{\circ} \mathrm{C}$ until DNA/RNA extraction and analysis. Control animals $(\mathrm{N}=3)$ were provided by the Center of Zoonozes Control, and necropsy after euthanasia was performed and cerebellum and lymph nodes were submitted to the same DNA/RNA procedures. 


\section{Virus samples - positive control}

Canine distemper virus vaccine samples (Onderstepoort and Rockborn) in Vero cells (African green monkey kidney) were used as positive controls. Samples were kindly supplied by Dr. Marilene Camargos from the Labovet Laboratory (Produtos Veterinários Ltda. - Feira de Santana, BA, Brazil).

\section{DNA isolation and electrophoresis}

Approximately $300 \mu \mathrm{L}$ peripheral blood, or $0.2 \mathrm{~g}$ cerebellum or lymphoid tissue was ground in $1 \mathrm{~mL}$ cell lysis buffer ( $320 \mathrm{mM}$ sucrose; $10 \mathrm{mM}$ Tris- $\mathrm{HCl}, \mathrm{pH} 7.5 ; 1 \mathrm{M}$ Tris-HCl, $\mathrm{pH} 7.5 ; 5 \mathrm{mM} \mathrm{MgCl} ; 1 \%(\mathrm{v} / \mathrm{v})$ Triton X-100), centrifuged at $4000 \mathrm{rpm}$ for $5 \mathrm{~min}$ and the supernatant discarded. Four hundred-microliter protein digestion buffer $(10 \mathrm{mM}$ Tris- $\mathrm{HCl}$, pH 7.5; $10 \mathrm{mM}$ EDTA, $\mathrm{pH} 8.0 ; 10 \mathrm{mM} \mathrm{NaCl} ; 0.5 \%$ SDS and $20 \mathrm{mg} / \mathrm{mL}$ proteinase $\mathrm{K}$ ) was added and incubated at $55^{\circ} \mathrm{C}$ for $2 \mathrm{~h}$ in a water bath. Samples were centrifuged at $13,000 \mathrm{rpm}$ for $5 \mathrm{~min}$ and DNA extracted from the supernatant using ethanol precipitation. A DNA pool of $3 \mathrm{CDV}$ - animals (for blood, lymph nodes and cerebellum), and $4 \mathrm{CDV}+$ animals (for blood, lymph nodes and cerebellum) was analyzed on $1.5 \%$ agarose gel by standard electrophoresis.

\section{RNA isolation and reverse transcription}

RNA was isolated from tissue $(100 \mathrm{mg})$, peripheral blood $(300 \mu \mathrm{L})$ and Vero cell homogenate $(300 \mathrm{~mL})$ using acid guanidinium thiocyanate-phenol-chloroform extraction (Chomczynski and Sacchi, 2006). Samples were treated with the Turbo DNA-free kit (Ambion Inc., Foster, CA, USA). First-strand complementary DNA (cDNA) was synthesized from $2 \mu \mathrm{g}$ total RNA using the Superscript first-strand synthesis system (Invitrogen Inc., Carlsbad, CA, USA). After denaturing the template RNA and primers (25 pmol of each reverse oligonucleotide primer) at $70^{\circ} \mathrm{C}$ for $10 \mathrm{~min}, 40 \mathrm{U}$ reverse transcriptase was added in the presence of RT buffer (50 mM KCl, $20 \mathrm{mM}$ Tris-HCl, pH 8.4), $4 \mu \mathrm{L}$ dNTP mix ( $250 \mu \mathrm{M}$ each), $40 \mathrm{U}$ RNase inhibitor and RNase-free water to complete the final volume. The reaction mixture (50 $\mu \mathrm{L}$ ) was incubated at $43^{\circ} \mathrm{C}$ for $1 \mathrm{~h}$, then stopped at $4^{\circ} \mathrm{C}$ and used immediately for PCR or kept at $-80^{\circ} \mathrm{C}$ until use.

\section{RT-PCR}

Canine distemper virus nucleocapsid cDNA and canine housekeeping gene S26 were amplified by conventional PCR, using positive control cDNA samples (infected Vero cells) and dog cDNA samples. Specific primers were designed for gel-based RT-PCR using the sequences obtained in GeneBank. Subsequently, all sequences were designed and analyzed using the Integrated DNA Technologies website program (http://www.idtdna.com), and specific primers that amplified a 319-bp amplicon for CDV and 75 bp for S26 were designed (Table 1). Exon 2 of rat angiotensinogen (AGT), which amplified a 298-bp amplicon was used as PCR control, using genomic DNA from rat. Conventional PCR occurred under the following cycling conditions: denaturation at $93^{\circ} \mathrm{C}$ for $1 \mathrm{~min}$, annealing at $56^{\circ} \mathrm{C}$ for $1 \mathrm{~min}$, and extension at $72^{\circ} \mathrm{C}$ for $1 \mathrm{~min}$, for 40 cycles. 
Table 1. PCR primers selected. Primers used for gel-based RT-PCR for CDV diagnosis (A), housekeeping gene S26 (B), and PCR control AGT (rat angiotensinogen; H). Primers used in real-time PCR for apoptosis related target genes (C, D, E, F and G), and normalizer gene S26 (B).

\begin{tabular}{|c|c|c|c|c|}
\hline & Primers & Sequence of the nucleotides (nt) & Size (nt) & Fragment length \\
\hline \multirow[t]{2}{*}{$\mathrm{A}$} & VCC01-F1 & 5'-CAG CAC CGT ACA TGG TTA TC-3' & $20 \mathrm{nt}$ & $319 \mathrm{bp}$ \\
\hline & VCC02-R2 & 5'-TAG CAT AAC TCC AGA GCA ATG-3' & $20 \mathrm{nt}$ & \\
\hline \multirow[t]{2}{*}{ B } & $\mathrm{S} 26 \mathrm{CF}-\mathrm{F} 1$ & 5'-CGT GCT TCC CAA GCT GTA CGT GA-3' & $24 \mathrm{nt}$ & $75 \mathrm{bp}$ \\
\hline & S26CF-R2 & 5'-CGA TTC CGG ACT ACC TTG CTG TG-3' & $23 \mathrm{nt}$ & \\
\hline \multirow[t]{2}{*}{$\mathrm{C}$} & CASP3BT/CF-F1 & 5'-TTC ATT ATT CAG GCC TGC CGA GG-3' & $24 \mathrm{nt}$ & $83 \mathrm{bp}$ \\
\hline & CASP3BT/CF-R2 & 5'-TTC TGA CAG GCC ATG TCA TCC TCA-3' & $24 \mathrm{nt}$ & \\
\hline \multirow[t]{2}{*}{$\mathrm{D}$} & CASP8CF-F1 & 5'-ACA AGG GCA TCA TCT ATG GCT CTG A-3' & $25 \mathrm{nt}$ & $70 \mathrm{bp}$ \\
\hline & CASP8CF-R2 & 5'-CCA GTG AAG TAA GAG GTC AGC TCA T-3' & $25 \mathrm{nt}$ & \\
\hline \multirow[t]{2}{*}{ E } & CASP9CF-F1 & 5'-TCA GTG ACG TCT GTG TTC AGG AGA-3' & $24 \mathrm{nt}$ & $97 \mathrm{bp}$ \\
\hline & CASP9CF-R2 & 5'-TTG TTG ATG ATG AGG CAG TAG CCG-3' & $24 \mathrm{nt}$ & \\
\hline \multirow[t]{2}{*}{$\mathrm{F}$} & BAXCF-F1 & 5'-TTC CGA GTG GCA GCT GAG ATG TTT-3' & $24 \mathrm{nt}$ & 79 bp \\
\hline & BAXCF-R2 & 5'-TGC TGG CAA AGT AGA AGA GGG CAA-3' & $24 \mathrm{nt}$ & \\
\hline \multirow[t]{2}{*}{$\mathrm{G}$} & BCL2CF-F1 & 5'-CAT GCC AAG AGG GAA ACA CCA GAA-3' & $24 \mathrm{nt}$ & $76 \mathrm{bp}$ \\
\hline & BCL2CF-R2 & 5'-GTG CTT TGC ATT CTT GGA TGA GGG-3' & $24 \mathrm{nt}$ & \\
\hline \multirow[t]{2}{*}{$\mathrm{H}$} & AGT01 & 5'-TCC ACA GAT CCG TGA TGA CTC-3' & $21 \mathrm{nt}$ & $298 \mathrm{bp}$ \\
\hline & AGT02 & 5'-GCA GCT CGC TGC CGA TCC TC-3' & $20 \mathrm{nt}$ & \\
\hline
\end{tabular}

\section{Real-time PCR}

Real-time PCR was carried out in an ABI Prism 7500 Sequence Detection System (Applied Biosystems, Foster City, CA, USA), using the fluorescent dye $\operatorname{Sybr}^{\circledR}$ Green Master Mix (Applied Biosystems). PCR were set up in a dedicated room, and gloves, face masks, and barrier tips used for all work. All samples were run in duplicate on 96-well optical PCR plates in a final reaction volume of $25 \mu \mathrm{L}$. The PCR parameters were 1 cycle at $50^{\circ} \mathrm{C}$ for $2 \mathrm{~min}, 1$ cycle at $95^{\circ} \mathrm{C}$ for $10 \mathrm{~min}, 40$ cycles at $95^{\circ} \mathrm{C}$ for $15 \mathrm{~s}$ and $60^{\circ} \mathrm{C}$ for $1 \mathrm{~min}$.

The primers used for PCR amplification of caspase-3, -8, -9, Bcl-2, Bax, S26, and CDV are listed in Table 1. The gene encoding the ribosomal protein S26 was used as an internal control to normalize target gene expression.

Specific primers were designed using the sequences obtained in GeneBank, through the Blast program (http://www.ncbi.nlm.nih.gov/blast/blast.cgi). Subsequently, all sequences were designed and analyzed using the Integrated DNA Technologies website program (Table 1).

The specificity of PCR products was confirmed by the single peak dissociation curves and by acrylamide gel electrophoresis showing that amplicons had the predicted size. Relative gene expression was calculated by using the $2^{-\Delta \Delta \mathrm{CT}}$ method, where CT is the threshold cycle (Livak and Schmittgen, 2001).

\section{Statistical analysis}

The PCR results were analyzed based on the $\Delta \mathrm{CT}$, which is the primary source of data variability (Yuan et al., 2006). The unpaired Student $t$-test was used to analyze expression levels of transcripts of the pro- and anti-apoptotic genes in peripheral blood, cerebellum and lymph nodes, comparing the groups of positive $(\mathrm{CDV}+)$ and negative (CDV-) animals. Statistical significance $(\mathrm{P}<0.05)$ was determined with the $t$-test in GraphPad Prism 5. 


\section{RESULTS}

\section{RT-PCR}

In the present study, we used RT-PCR to diagnosis CDV in 20 dogs presenting clinical signs suggesting $\mathrm{CD}$ and 12 dogs without any clinical signs of CDV infection. PCR results confirmed CDV positivity in 12 of $20(60 \%)$ animals previously showing CD clinical signs, by amplification of a 319-bp fragment (Figure 1). Furthermore, 8 of 12 non-suspected animals were confirmed negative in both conventional and real-time PCR. The amplification of S26 (used as the normalizer), was observed in all samples (Figure 1). A total of 20 selected samples were then used for gene expression analysis of pro-apoptotic caspase-3, $-8,-9$ and Bax, and anti-apoptotic Bcl-2 targets by means of relative quantitative real-time PCR.

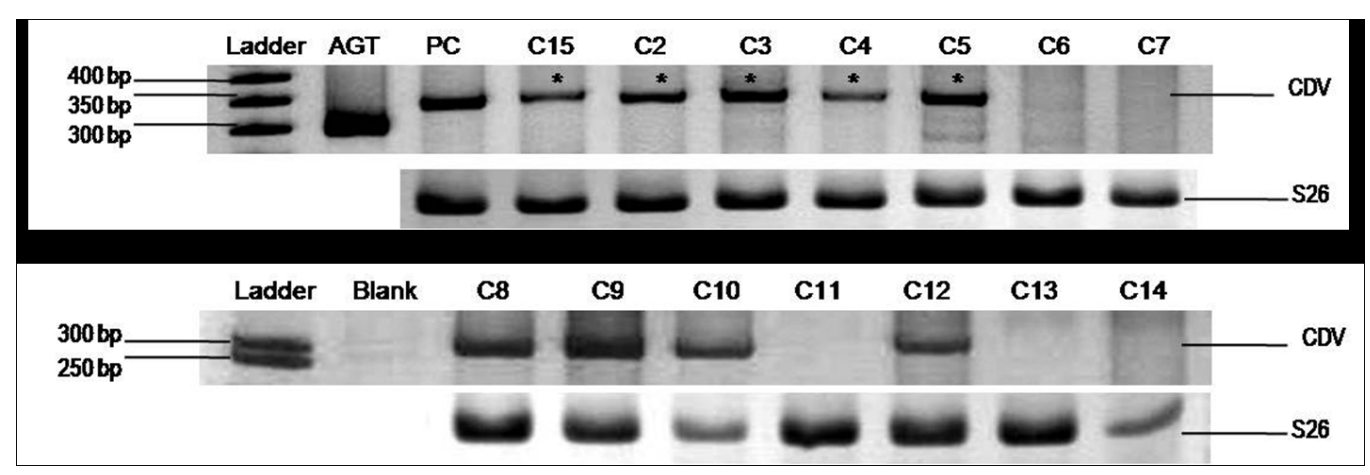

Figure 1. Typical canine distemper virus (CDV) gel-based conventional PCR diagnostic test of total blood using VCC01/VCC02 primers. Samples are from 12 clinically suspected animals (C1-C12) and 2 healthy animals $(\mathrm{C} 13, \mathrm{C} 14)$. Three microliters of the amplification reaction was applied and visualized on a silver stained $8 \%$ polyacrylamide gel after electrophoresis at $100 \mathrm{~V}$ for $50 \mathrm{~min}$. The CDV-specific amplicon of $319 \mathrm{bp}$ is indicated by asterisk and the S26 75 bp normalizer is shown below each sample. Ladder = 50-bp DNA ladder (0.3 $\mu \mathrm{g})$; AGT = rat angiotensinogen, 298-bp amplicon PCR control; PC = positive control Vero cells infected with CDV; Blank = no template, negative control.

\section{Hematological analysis}

The hemogram results for CDV- and CDV+ dogs did not present a significant difference in the absolute lymphocyte, neutrophil, eosinophil and monocyte counts or in total leukocyte counts $(\mathrm{P}>0.05)$.

\section{DNA electrophoresis}

DNA from the cerebellum and retropharyngeal lymph node of infected animals that presented systemic and neurological CD signs showed the ladder pattern of DNA (Figure 2), and apoptosis was characterized by typical DNA fragmentation on agarose gel, while DNA from peripheral blood cells did not (Figure 2). Control animals showed more intact high molecular DNA than infected dogs, except when comparing blood samples. 


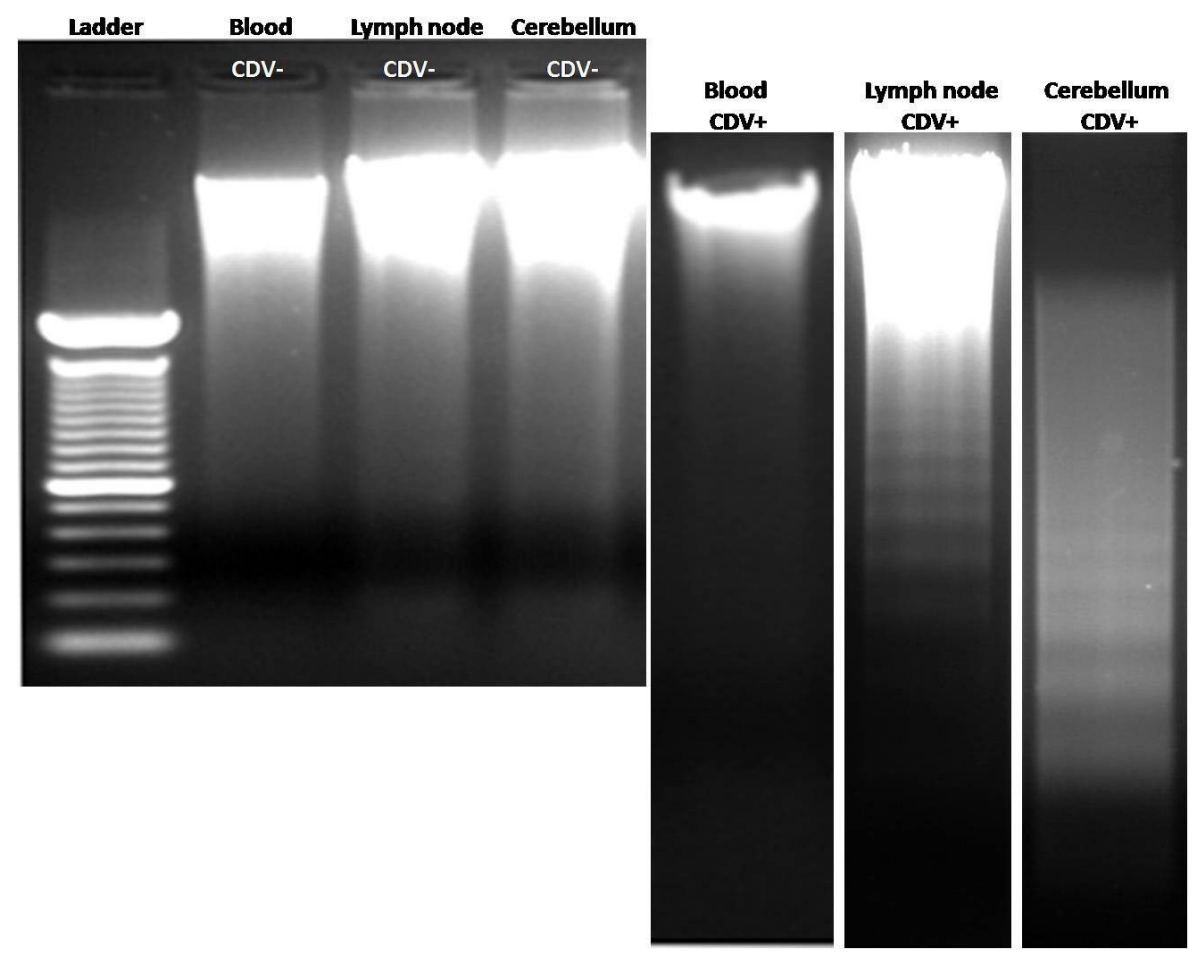

Figure 2. Typical agarose gel electrophoresis of DNA extracted from peripheral blood, lymph node and cerebellum control (canine distemper virus, CDV- / pool from 3 animals), and peripheral blood, lymph node and cerebellum of animals naturally infected with CDV (CDV+ / pool from 4 animals). Electrophoresis was performed on a $1.5 \%$ agarose gel, $1 \mathrm{X}$ TAE, $1 \mathrm{~h}$ at $100 \mathrm{~V}$. Ladder = gene ruler - 100-bp DNA ladder (MBI); $20 \mu \mathrm{L}$ of each sample was used. Qualitative differences in high molecular DNA and in the ladder pattern of degradation are observed between controls and infected animals, except on peripheral blood.

\section{Real-time PCR}

Real-time PCR did not show statistically significant differences in peripheral blood samples from $\mathrm{CDV}+(\mathrm{N}=12)$ and $\mathrm{CDV}-(\mathrm{N}=8)$ dogs in expression of caspase- $3,-8,-9$, Bax and Bcl-2 $(\mathrm{P}>0.05)$. The expression of caspase- 3 and -8 was significantly higher in the lymph nodes of $\mathrm{CDV}+(\mathrm{N}=4)$ than in $\mathrm{CDV}-(\mathrm{N}=3)$ dogs (caspase-3: fold change $=3.29,3.2 \pm 0.4$; caspase- 8 : fold change $=3.05,3.0 \pm 0.2 ; \mathrm{P}<0.05$, Figure 3 ). Therefore, there were no statistically significant differences in the expression of caspase-9, Bax and Bcl-2 when comparing lymph nodes from $\mathrm{CDV}+$ and $\mathrm{CDV}-\mathrm{dogs}(\mathrm{P}>0.05)$. In addition, expression of caspase- $3,-8$, -9 and Bax was significantly higher in the cerebellum of $\mathrm{CDV}+(\mathrm{N}=4)$ than in $\mathrm{CDV}-(\mathrm{N}=3)$ dogs (caspase-3: fold change $=17.47,3.2 \pm 0.4$; caspase-8: fold change: $19.93,19.74 \pm 0.23$; caspase-9: fold change $=1.97,1.9 \pm 0.1 ;$ Bax: fold change $=9.78,9.7 \pm 1.4 ; \mathrm{P}<0.05$; Figure 4). Thus, as in lymph nodes, there were no statistically significant differences in the expression of $\mathrm{Bcl}-2$ between the $\mathrm{CDV}+$ and $\mathrm{CDV}$ - groups $(\mathrm{P}>0.05)$. Dissociation curves were unique for each amplicon and confirmed gene target specificity. 
A

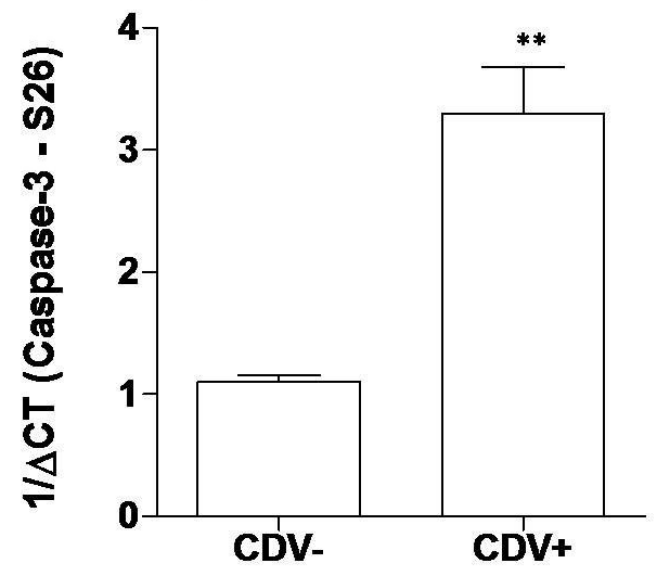

B

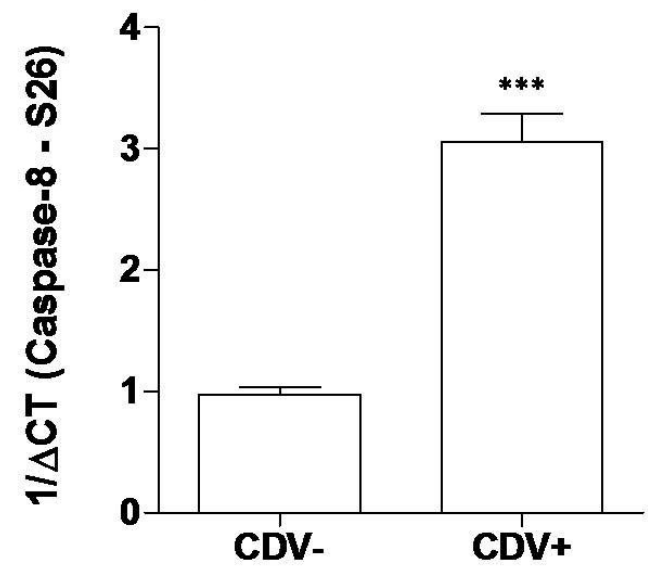

Figure 3. Expression of caspase-3 (panel A) and caspase-8 (panel B) mRNA in retropharyngeal lymph node of canine distemper virus $(\mathrm{CDV}+)$ dogs $(\mathrm{N}=4)$ and $\mathrm{CDV}-(\mathrm{N}=3)$. For better clarity, data are plotted as means $\pm \mathrm{SEM}$ of $1 / \triangle \mathrm{CT}$ (where $\mathrm{CT}$ is the threshold cycle), which is directly proportional to the relative gene expression (fold change). ${ }^{* *} \mathrm{P}<0.01$ and ${ }^{* * *} \mathrm{P}<0.001$ (unpaired $t$-test), analysis performed in GraphPad Prism 5.
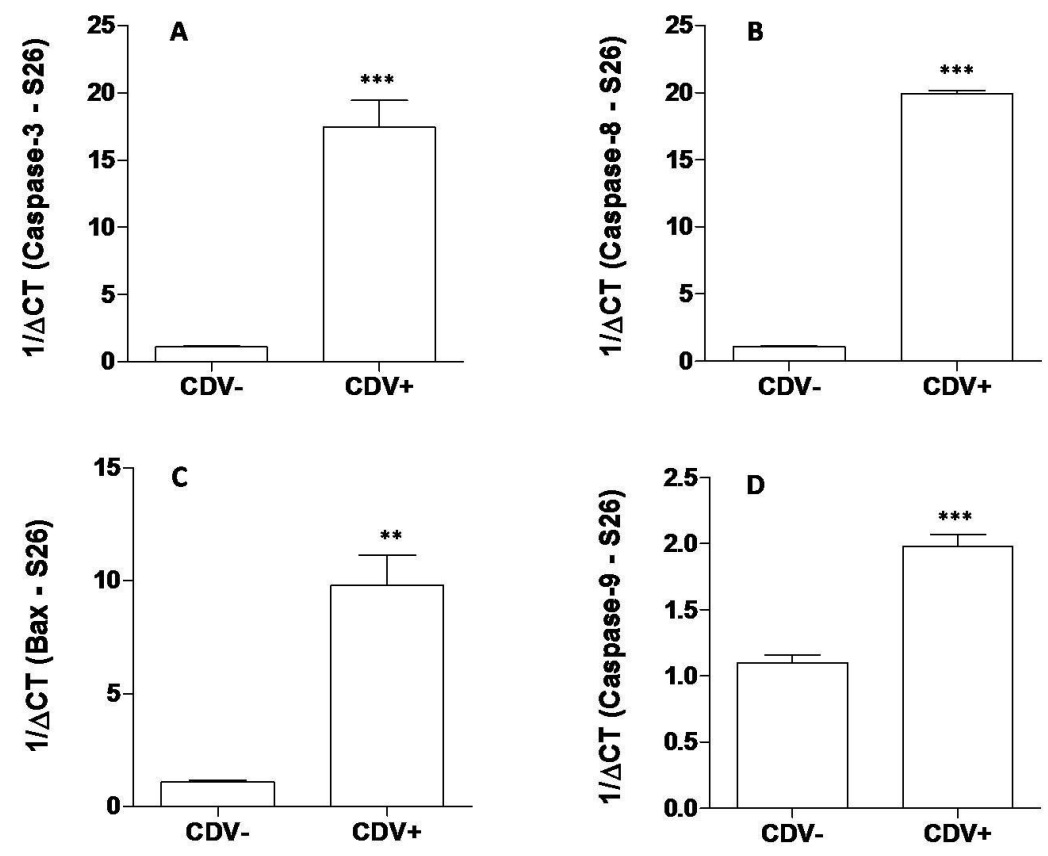

Figure 4. Expression of caspase-3 (panel A), caspase-8 (panel B), Bax (panel C), and caspase-9 (panel D) mRNA in cerebellum of canine distemper virus $(\mathrm{CDV}+) \operatorname{dogs}(\mathrm{N}=4)$ and $\mathrm{CDV}-(\mathrm{N}=3)$. For better clarity, data are plotted as means \pm SEM of $1 / \triangle \mathrm{CT}$ (where $\mathrm{CT}$ is the threshold cycle), which is directly proportional to the relative gene expression (fold change). ${ }^{* * \mathrm{P}}<0.01$ and ${ }^{* * *} \mathrm{P}<0.001$ (unpaired $t$-test), analysis performed in GraphPad Prism 5. 


\section{DISCUSSION}

The present study shows that CDV infection induces apoptosis in lymph node and in the cerebellum through enhanced expression of caspases. Moreover, we have shown that expression of caspase- 3 and -8 is increased in the lymph nodes of CDV-infected animals compared to non-infected animals, and that the expression of caspase-3, $-8,-9$ and Bax is increased in the cerebellum of CDV-infected animals compared to those non-infected.

This study was based on 20 dogs that presented clinical signs suggesting CD and 12 dogs without any clinical signs for CD screened by conventional gel-based RT-PCR for CDV detection. PCR results confirmed CDV positivity in 12 of $20(60 \%)$ of the suspected animals and negativity in 8 of $12(67 \%)$ non-suspected animals. The use of RT-PCR for CDV detection has been demonstrated to be a useful tool in diagnosis and research, capable of detecting CDV in different specimens (Frisk et al., 1999).

Apoptosis plays an important role in lymphoid depletion induced by CDV. Apoptotic cells are seen in blood smears of CDV-infected animals, and CDV infection caused lymphocyte apoptosis at 3 days post-infection in spite of the absence of detectable leukocyte infection (Schobesberger et al., 2005). In our study, it was not possible to detect lymphocyte apoptosis in peripheral blood. There were no differences in mRNA expression of apoptotic genes, and no differences in hematological results comparing CDV+ and CDV- animals. Dogs used in our study were naturally infected by CDV, probably for longer than 1 week. Schobesberger et al. (2005) performed an experimental infection in dogs, and blood samples were analyzed at 3, 6 and 10 days post-infection. Clinical symptoms were checked daily, and it was observed that leukocyte numbers dropped in all animals when compared to the values before the challenge, but on 10 days post-infection leukocyte numbers were normal again. To begin to address changes in expression of apoptotic genes in peripheral blood samples, it was necessary to experimentally inoculate animals and analyze blood samples during the first week of infection.

Canine distemper virus infection induced apoptosis in lymphoid tissue (Moro et al., 2003b) and in the cerebellum (Moro et al., 2003a), but until now the molecular mechanisms of apoptosis in vivo have remained unknown. Recently, Kajita et al. (2006) demonstrated that CDV infection may induce apoptosis in Vero cells through caspase- 3 and -8 activation. In that study, a gel-based semiquantitative RT-PCR analysis for Fas, Bcl-2 and Bax was performed. Their results demonstrated no changes in expression for either intrinsic anti-apoptotic pathway Bcl-2 or intrinsic pro-apoptotic pathway Bax mRNAs. However, the extrinsic pro-apoptotic pathway Fas receptor mRNA expression was increased, suggesting involvement of the extrinsic pathway in apoptosis induction by CDV in Vero cells.

This study presents the first data in vivo of the molecular apoptosis mechanisms induced by CDV. Results of caspase- 3 and -8 mRNA expression, normalized to the invariant housekeeping gene S26, showed in the lymph node that caspase-3 in CDV+ dogs was 3.29 times higher than in CDV- dogs (Figure 3A). Similarly, our results showed that caspase-8 mRNA expression was also significantly increased in CDV+ animals by 3.05 -fold compared to CDV- dogs (Figure 3B). In addition, results from cerebellum demonstrated that mRNA expression of caspase-3 (17.47-fold change), caspase-8 (19.93-fold change), caspase-9 (1.97fold change) and Bax (9.78-fold change) were significantly increased in CDV-infected animals compared to non-infected animals (Figure 4A-D). Bcl-2 mRNA expression showed no significant change in CDV+ and CDV- dogs. Apoptosis normally occurs in lymphoid tissue, 
rather than in cerebellum, which normally has no apoptosis. This could explain the difference in mRNA expression levels of apoptotic genes in lymph nodes compared to the cerebellum in $\mathrm{CDV}+$ and CDV- animals.

In the lymph nodes and cerebellum of CDV+ dogs, DNA showed a greater degree of genomic fragmentation, suggesting a higher incidence of apoptosis in this tissue related to CDV infection, as observed in Figure 2. However, no genomic fragmentation indicating apoptosis was observed in blood samples of CDV- and in CDV+ dogs, and these data are consistent with the hematological and molecular results, which did not show any difference in leukocyte counts and mRNA expression when comparing blood samples from dogs infected and non-infected by CDV.

Recently, it has been reported that several viral proteins can induce apoptosis of infected cells, for example VP3 of CAV (Kawanishi, 1997), EIA of the adenovirus (Rao et al., 1992) and HA of the influenza virus (Olsen et al., 1996). Thus, it is not known if any CDV protein can induce apoptosis, or if apoptosis is a defense against CDV, or if apoptosis is a way for the virus to spread to other cells. Further study is needed to evaluate the CDV protein, its relation to apoptosis, and studies of apoptosis and host-parasite interaction. Based on the present findings in vivo and other studies in vitro, a very important conclusion is that CDV may induce apoptosis by the activation of caspase- 3 through caspase- 8 signaling, but in the cerebellum both pathways can be triggered together: caspase- 3 through caspase- 8 signaling, and caspase- 3 through mitochondrial signaling.

\section{ACKNOWLEDGMENTS}

This study was approved by the Ethics Committee of the Department of Pathology at the Universidade Federal de Minas Gerais (UFMG) in Brazil. We would like to thank the National Council for Scientific and Technological Development (Conselho Nacional de Desenvolvimento Científico e Tecnológico - CNPq), and the State of Minas Gerais Research Foundation (Fundação de Amparo à Pesquisa do Estado de Minas Gerais - FAPEMIG) for financial support, and Dr. Marilene Camargos for the CDV strains (Labovet Laboratory, Produtos Veterinários Ltda., Feira de Santana, BA, Brazil).

\section{REFERENCES}

Adams JM and Cory S (1998). The Bcl-2 protein family: arbiters of cell survival. Science 281: 1322-1326.

Adams JM and Cory S (2002). Apoptosomes: engines for caspase activation. Curr. Opin. Cell Biol. 14: 715-720.

Ameisen JC and Capron A (1991). Cell dysfunction and depletion in AIDS: the programmed cell death hypothesis. Immunol. Today 12: 102-105.

Banda NK, Bernier J, Kurahara DK, Kurrle R, et al. (1992). Crosslinking CD4 by human immunodeficiency virus gp120 primes T cells for activation-induced apoptosis. J. Exp. Med. 176: 1099-1106.

Blixenkrone-Moller M, Svansson V, Have P, Orvell C, et al. (1993). Studies on manifestations of canine distemper virus infection in an urban dog population. Vet. Microbiol. 37: 163-173.

Chomczynski P and Sacchi N (2006). The single-step method of RNA isolation by acid guanidinium thiocyanate-phenolchloroform extraction: twenty-something years on. Nat. Protoc. 1: 581-585.

Clem RJ, Cheng EH, Karp CL, Kirsch DG, et al. (1998). Modulation of cell death by Bcl-XL through caspase interaction. Proc. Natl. Acad. Sci. U. S. A. 95: 554-559.

Finucane DM, Bossy-Wetzel E, Waterhouse NJ, Cotter TG, et al. (1999). Bax-induced caspase activation and apoptosis via cytochrome c release from mitochondria is inhibitable by Bcl-xL. J. Biol. Chem. 274: 2225-2233.

Frisk AL, Konig M, Moritz A and Baumgartner W (1999). Detection of canine distemper virus nucleoprotein RNA by 
reverse transcription-PCR using serum, whole blood, and cerebrospinal fluid from dogs with distemper. J. Clin. Microbiol. 37: 3634-3643.

Griot C, Vandevelde M, Schobesberger M and Zurbriggen A (2003). Canine distemper, a re-emerging morbillivirus with complex neuropathogenic mechanisms. Anim. Health Res. Rev. 4: 1-10.

Guo A and Lu CP (1998). Regulation of cell apoptosis by virus infection. Chinese J. Vet. Med. 7: 46-47.

Guo A and Lu C (2000). Canine distemper virus causes apoptosis of Vero cells. J. Vet. Med. B Infect. Dis. Vet. Public Health 47: 183-190.

Iwatsuki K, Okita M, Ochikubo F, Gemma T, et al. (1995). Immunohistochemical analysis of the lymphoid organs of dogs naturally infected with canine distemper virus. J. Comp. Pathol. 113: 185-190.

Kajita M, Katayama H, Murata T, Kai C, et al. (2006). Canine distemper virus induces apoptosis through caspase-3 and -8 activation in Vero cells. J. Vet. Med. B Infect. Dis. Vet. Public Health 53: 273-277.

Kawanishi M (1997). Epstein-Barr virus BHRF1 protein protects intestine 407 epithelial cells from apoptosis induced by tumor necrosis factor alpha and anti-Fas antibody. J. Virol. 71: 3319-3322.

Krakowka S, Cockerell G and Koestner A (1975). Effects of canine distemper virus infection on lymphoid function in vitro and in vivo. Infect. Immun. 11: 1069-1078.

Krakowka S, Higgins RJ and Koestner A (1980). Canine distemper virus: review of structural and functional modulations in lymphoid tissues. Am. J. Vet. Res. 41: 284-292.

Kumagai K, Yamaguchi R, Uchida K and Tateyama S (2004). Lymphoid apoptosis in acute canine distemper. J. Vet. Med. Sci. 66: 175-181.

Lam KM and Vasconcelos AC (1994). Newcastle disease virus-induced apoptosis in chicken peripheral blood lymphocytes. Vet. Immunol. Immunopathol. 44: 45-56.

Livak KJ and Schmittgen TD (2001). Analysis of relative gene expression data using real-time quantitative PCR and the 2(-Delta Delta C(T)) Method. Methods 25: 402-408.

Manon S, Chaudhuri B and Guerin M (1997). Release of cytochrome c and decrease of cytochrome c oxidase in Baxexpressing yeast cells, and prevention of these effects by coexpression of Bcl-xL. FEBS Lett. 415: 29-32.

Moro L, Martins AS, Alves CM, Santos FG, et al. (2003a). Apoptosis in the cerebellum of dogs with distemper. J. Vet. Med. B Infect. Dis. Vet. Public Health 50: 221-225.

Moro L, de Sousa MA, de Moraes AC, de Araujo Santos FG, et al. (2003b). Apoptosis in canine distemper. Arch. Virol. 148: 153-164.

Olsen CW, Dybdahl-Sissoko N and Hinshaw VS (1996). The influence of calcium and reactive oxygen species on influenza virus-induced apoptosis. Cell Death Differ. 3: 191-197.

Oltvai ZN, Milliman CL and Korsmeyer SJ (1993). Bcl-2 heterodimerizes in vivo with a conserved homolog, Bax, that accelerates programmed cell death. Cell 74: 609-619.

Pringle CR (1999). Virus taxonomy - 1999. The universal system of virus taxonomy, updated to include the new proposals ratified by the International Committee on Taxonomy of Viruses during 1998. Arch. Virol. 144: 421-429.

Rao L, Debbas M, Sabbatini P, Hockenbery D, et al. (1992). The adenovirus E1A proteins induce apoptosis, which is inhibited by the E1B 19-kDa and Bcl-2 proteins. Proc. Natl. Acad. Sci. U. S. A. 89: 7742-7746.

Schobesberger M, Summerfield A, Doherr MG, Zurbriggen A, et al. (2005). Canine distemper virus-induced depletion of uninfected lymphocytes is associated with apoptosis. Vet. Immunol. Immunopathol. 104: 33-44.

Shimizu S, Eguchi Y, Kamiike W, Funahashi Y, et al. (1998). Bcl-2 prevents apoptotic mitochondrial dysfunction by regulating proton flux. Proc. Natl. Acad. Sci. U. S. A. 95: 1455-1459.

Slee EA, Adrain C and Martin SJ (2001). Executioner caspase-3, -6, and -7 perform distinct, non-redundant roles during the demolition phase of apoptosis. J. Biol. Chem. 276: 7320-7326.

Takizawa T, Matsukawa S, Higuchi Y, Nakamura S, et al. (1993). Induction of programmed cell death (apoptosis) by influenza virus infection in tissue culture cells. J. Gen. Virol. 74 (Pt 11): 2347-2355.

Vandevelde M and Zurbriggen A (2005). Demyelination in canine distemper virus infection: a review. Acta Neuropathol. 109: $56-68$

Wajant H (2002). The Fas signaling pathway: more than a paradigm. Science 296: 1635-1636.

Wunschmann A, Kremmer E and Baumgartner W (2000). Phenotypical characterization of T and B cell areas in lymphoid tissues of dogs with spontaneous distemper. Vet. Immunol. Immunopathol. 73: 83-98.

Yuan JS, Reed A, Chen F and Stewart CN Jr (2006). Statistical analysis of real-time PCR data. BMC Bioinformatics 7: 85. 